\title{
Variability of Water Exchanges Through the Strait of Hormuz
}

\section{Panagiotis Vasou1, Vassilios Vervatis2, George Krokos1, Ibrahim Hoteit1 and Sarantis Sofianos2}

1Earth Science and Engineering Department, King Abdullah University of Science and Technology, Thuwal, Saudi Arabia.

${ }_{2}$ Division of Environmental Physics, National and Kapodistrian University of Athens, Athens, Greece.

Corresponding author: Panagiotis Vasou (panagiotis.vasou@kaust.edu.sa)

\section{ORCID of the authors:}

Vasou P.: 0000-0002-5788-9686

Vervatis V.: 0000-0002-8862-8155

Krokos G.: 0000-0001-7428-0066

Hoteit I.: 0000-0002-3751-4393

Sofianos S.: 0000-0001-6325-513X

Acknowledgments This work was supported by funds from the Office of Sponsored Research (OSR) at King Abdullah University of Science and Technology (KAUST) under the Competitive Research Grant (CRG) program (Grant \# URF/1/2979-01-01), the IKY Scholarships Programme co-financed by the European Union (European Social Fund-ESF) and the Greek national funds through the action entitled "Reinforcement of Postdoctoral Researchers", in the framework of the Operational Programme "Human Resources Development Programme, Education and Lifelong Learning" of the National Strategic Reference Framework (NSRF) 2014-2020. Computational time granted from the Greek Research \& Technology Network (GRNET) in the National HPC facility - ARIS - under project ID PR004003 is acknowledged. 


\begin{abstract}
The variability of the water mass exchange between the Arabian Gulf and the Indian Ocean is investigated using a high-resolution $\left(1 / 36^{\circ}\right)$ ocean model. We focus on the period from December 1996 to March 1998, having as reference in-situ measurements at the Strait of Hormuz. Previous studies, based on models and observations, suggested a perpetual deep outflow, mainly in the southern part of the Strait, and a variable flow in the upper layers. In the present study, we confirm that there is a permanent core of a deep outflow in the Strait at depths greater than $40 \mathrm{~m}$, characterized by high-salinity waters. In addition, we show that there is a seasonal signal in the upper layers net flow in the southern part of the Strait, altering from net inflow during winter/spring to net outflow during summer/fall. The mean annual inflow through the Strait is estimated at 0.22 $\pm 0.01 \mathrm{~Sv}$ and the deep outflow at $0.147 \pm 0.01 \mathrm{~Sv}$. The water mass exchange through the Strait is controlled by synoptic processes with high variability net transport fields. These processes characterize the structure and the intensity of the transport patterns, exhibiting two to five days period. On synoptic time scales winds drive an immediate baroclinic flow at the Strait of Hormuz, affecting mostly the upper layers, and a quasi-barotropic flow that peaks approximately 2 days later.
\end{abstract}

Key Words: Arabian Gulf, Strait of Hormuz, ocean modeling, water mass exchange, synoptic processes

\title{
1 Introduction
}

The Arabian Gulf (hereafter called the Gulf), located between the Arabian Peninsula and southwestern Iran, is connected to the Gulf of Oman and the Arabian Sea through the Strait of Hormuz (SoH) (Fig. 1). The Gulf is a shallow, semi-enclosed sea with about $990 \mathrm{~km}$ length and width ranging from a minimum of $56 \mathrm{~km}$ to a maximum of $340 \mathrm{~km}$. It is the source of the Arabian Gulf Water (AGW, also known as Persian Gulf Water), one of the most saline water masses in the global ocean. During winter, formation of dense waters takes place in the northern part of the Gulf (Swift and Bower 2003, Yao and Johns 2010, Pous et al. 2015), and on the southern shelves of the Gulf (Kämpf and Sadrinasab 2005, Yao and Johns 2010, Pous et al. 2015, Al Azhar et al. 2016). In contrast to other semi enclosed basins, the Mediterranean Sea and the Red Sea, the Gulf has a wider strait and small depth (an average of $35 \mathrm{~m}$ and a maximum of about $110 \mathrm{~m}$ near the SoH) and has no prominent sill to constrain the outflow (Johns et al. 2003). However, Thoppil and Hogan (2009) suggested that the circulation can be constrained by a sill, located in the proximity of $26^{\circ} \mathrm{N}$, $55.4^{\circ} \mathrm{E}$, south of the $\mathrm{SoH}$. The sill can affect the outflow variability and restrain the water mass exchange.

The Gulf is a major oil region, and the SoH one of the most important waterways for oil transport. As a result, there is high risk of oil spills and leaks that could lead to harmful ecological impacts (Essa et al. 2005; Zhao et al. 2014, 2015). The Gulf is also the primary point of supply of water for industrial, as well as domestic usage, for all surrounding countries. The quality of this water is highly affected by dust storms, which transport a large amount of nutrients and also influence the ecosystem's balance (Gherboudj and Ghedira, 2014). Events of Harmful Algal Blooms have caused in the past problems to water security and disturbed the water supply (Richlen et al. 2010; Al Shehhi et al. 2014; Zhao and Ghedira 2014). The Gulf is impacted by various environmental aspects, and therefore, understanding its dynamics, and especially the exchanges with the open ocean, is of high significance. 
A thorough analysis of the circulation in the Gulf was presented by Reynolds (1993). Incorporating all available observations, including those of Emery (1956), Brewer et al. (1978), and Brewer and Dyrssen (1985), the authors suggested that low salinity water from the Arabian Sea enters primarily from the northern part of the SoH, and flows westward along the southern coast of Iran. This water is driven to the northwestern and shallow southeastern areas of the Gulf by a general cyclonic circulation, where it is transformed to highly saline and dense water, sinking to the bottom and finally exiting through the deep part of the SoH.

The SoH plays a critical role in determining the circulation in the Gulf, by confining the water exchange between the Gulf and the open ocean. Water exchange through the $\mathrm{SoH}$ is forced primarily by large annual evaporation, which drives a shallow inflow of Indian Ocean Surface Water (IOSW) from the Arabian Sea, and a deep outflow of dense, hypersaline water (AGW). The low salinity inflow occurs mainly through the northern side of the SoH along the Iranian coast (Brewer et al. 1978; Hunter 1986; Reynolds 1993). The high-salinity outflow is mostly confined to the deeper southern part of the SoH (Chao et al. 1992; Johns et al. 2003). Swift and Bower (2003) suggested that on synoptic time scales, the sea surface height difference between the Gulf and the Gulf of Oman controls the inflow-outflow transport through the SoH, but other studies suggested baroclinic forcing due to density gradients as the main driving force (Chao et al. 1992, Yao and Johns 2010). The effect of tides is considerably low in the Gulf due to weak residual tidal currents, but important for assessing diurnal and semi-diurnal reversible flows and tidal fronts, especially at the SoH (Matsuyama et al. 1998; Pous et al. 2013).

Johns et al. (2003) investigated the water exchanges through the SoH using hydrographic and moored acoustic Doppler current profiler data $\left(56.08^{\circ} \mathrm{E}\right.$ and $26.26^{\circ} \mathrm{N}$; Fig. 1, white dots) spanning the period from December 1996 to March 1998. They proposed a three-dimensional pattern of inflow and outflow at the SoH, characterized by a deep outflow of highly saline water, banked against the southern part of the SoH and a varying pattern in the upper layers. A surface inflow of fresher waters occurs in the northern part and an upper layer outflow in the southern part of the SoH. The upper layer outflow exhibits strong seasonal variability, with higher salinity during winter that switches to a fresher inflow in spring. They also evidenced high variability at near surface currents, that present large amplitude and short-term fluctuations. Johns et al. (2003) observations are the only well- sampled time series in the SoH that can be used to analyze the flow, but covers only a small part of the Strait. Their results were based on extrapolating these local salinity and temperature measurements and time-gapped velocity data, covering the period from December 1996 to early May 1997 and from early August to November 1997.

As a general framework, a modeling study provides the means to compute the transport and examine its variability using simulated velocity profiles across the strait, as opposed to extrapolating information from in-situ measurements subject to representativity sampling errors. This modelling study aims at addressing open questions in relation to the water exchange transport in the SoH, following previous modelling studies in recent years (Thoppil and Hogan 2009, Yao and Johns 2010, Pous et al 2015). In particular, we focus on investigating the high-frequency variability of the flow and for this, we have configured a high-resolution model in the horizontal and vertical directions. For the vertical grid we have configured a very detailed vertical representation of the water column structure using up to 50 levels, important to resolve the deepest parts of the Gulf, including the water exchange transport in the $\mathrm{SoH}$ and the outflow in the deepest parts of the Gulf of Oman. 
Thoppil and Hogan (2009) used the Hybrid Coordinate Ocean Model (HYCOM; Bleck et al. 2002), with $1 \mathrm{~km}$ horizontal resolution and a 16-layer vertical configuration, having as reference the year 2005. They simulated intermittent changes in the salinity outflow, presenting salinity pulses of short duration in the SoH, in agreement with Johns et al. (2003)'s observations. The salinity outflow variations were linked with the formation of mesoscale cyclonic eddies. The fluctuations of the wind forcing induced the transport variability, triggered by baroclinic instability processes explaining the formation of eddies. The upper $50 \mathrm{~m}$ flow exhibited high frequency variability with frequent reversals, based on a few representative daily snapshots of mean currents.

The same model (HYCOM; Bleck 2002, Halliwell 2004) was later used by Yao and Johns (2010), with a different setup using $5 \mathrm{~km}$ horizontal resolution and 13 vertical levels. Yao and Johns (2010) suggested that the main mechanism controlling the inflow-outflow transport through the SoH was the baroclinic response due to density gradient. Another finding was that the surface inflow through the Strait exhibited strong seasonal variability. The inflow was enhanced in the northern part of the Gulf during summer. In winter, the inflow shifts towards the southern part of the Gulf, as a result of the intense northwesterly winds. In the same study, the transport outflow through the deepest parts of the Strait was found maximum (minimum) during summer (winter). The latter, implies that the water exchange through the Strait is mainly driven by buoyancy fluxes over the Gulf, controlling also the seasonality of the outflow.

Pous et al. (2015) used a hydrostatic (shallow-water) model in spherical coordinates (MARS3d; Lazure and Dumas, 2008), with $9 \mathrm{~km}$ horizontal resolution and 30 vertical levels. Sensitivity experiments were also performed with a higher resolution $(3 \mathrm{~km})$ version of the model. The study showed a seasonal to interannual variability for the net transport, with high intra-seasonal outflow variability and interannual fluctuations driven by density gradients. It was concluded that an optimal model resolution to properly resolve the water exchanges in the Strait is about $3 \mathrm{~km}$, pertaining to the fact that the exchange is affected by mesoscale processes and synoptic wind variability.

In this study, we investigate the variability of the water mass exchange through the $\mathrm{SoH}$, focusing on synoptic time scales, in relation to the local wind forcing. We provide new insights on the spatiotemporal variability of the transport, based on the detailed representation of the Strait and examine the transport fluctuations across a broad frequency spectrum. We performed an ocean model simulation validated with in-situ observations, over the years 1996 to 1998. The paper is organized as follows. The model configuration, the experiments and the methods are described in Section 2. The results are presented in Section 3, including a model assessment against in-situ observations. A brief summary and the conclusions of this study are presented in Section 4 .

\section{Experimental environment}

\subsection{Model configuration}

We use a regional configuration of NEMO version 3.6 (Nucleus for European Modelling of the Ocean; http://www.nemo-ocean.eu/; Madec 2012), covering the Arabian Gulf and the Gulf of Oman $\left(47.58^{\circ} \mathrm{E}\right.$ to $59.75^{\circ} \mathrm{E}$ and $22.48^{\circ} \mathrm{N}$ to $30.44^{\circ} \mathrm{N}$; Fig. 1$)$.

The three-dimensional primitive equations of the present configuration are discretized on a $1 / 36^{\circ}$ curvilinear Arakawa C-grid ( 2.4-2.8 km; $439 \times 334$ grid points) assuming hydrostatic and Boussinesq approximations, based on the ORCA tripolar grid commonly used in NEMO 
configurations (Barnier et al. 2006). At this resolution, the ocean model is eddy-resolving in the deepest parts of the domain and eddy-permitting in the shallower regions, with a Rossby radius of deformation of a few km only (Hyder et al. 2014). The regional domain (hereafter ARG36) is configured with the SIREN tool, as an exact 1:3 subset of the global operational system PSY4V3R1 (http://marine.copernicus.eu/). The vertical discretization has $50 \mathrm{z}$-levels, with partial steps to allow for an accurate representation of the seabed. The bathymetry is based on GEBCO_2014 dataset (Weatherall et al. 2015). The ARG36 grid set-up, based on the parent system PSY4V3R1, simplifies the nesting procedure, using as initial and open boundary conditions a prescribed climatology based on the analysis fields ( $\mathrm{SSH}, \mathrm{T}, \mathrm{S}, \mathrm{U}, \mathrm{V}$ ) from the archives of CMEMS (http://marine.copernicus.eu/). The eastern boundary of the ocean model is set in the Arabian Sea at $59.75^{\circ} \mathrm{E}$, including a buffer zone of 10 grid points.

A split-explicit free surface (time-splitting) scheme is used to adequately simulate fast external gravity waves (Shchepetkin and McWilliams 2005). The model simulates tides and a Flather (1994) scheme is imposed as a radiation condition to add the tidal harmonic forcing in the open boundary. The tidal components are provided by the TPXO7.2 global model of ocean tides (Egbert and Erofeeva 2002) as the sum of 11 constituents (M2, S2, K2, N2, K1, O1, P1, Q1, M4, Mf, Mm). The baroclinic update of the depth varying prognostic variables is set at $150 \mathrm{~s}$.

The major river source in the Arabian Gulf is composed by the Tigris, Euphrates and Karun rivers and is called Shatt-Al-Arab. The river is imposed in the model as a surface boundary freshwater flux of constant salinity 0.1 . The river runoff varies in a sinusoidal way, with minimum values of $350 \mathrm{~m} 3 / \mathrm{s}$ in October and maximum of $650 \mathrm{~m} 3 / \mathrm{s}$ in April (Kämpf and Sadrinasab 2006).

The meteorological fields are provided by the DRAKKAR Forcing Set 5.2 (DFS5.2; Dussin et al. 2014), using a bulk core formulation with time interpolation between the ocean model time-steps. Weighting files are supplied to map the data between the atmospheric and ocean model different grid meshes, using bilinear interpolation "on the fly" for the heat/freshwater fluxes and bicubic for the wind forcing. The implementation of the radiative flux is parametrised using a two-band light penetration. There are no surface restoring terms on observed or climatological SST and SSS variables.

In terms of physics, we use the Generic Length Scale (GLS) turbulent closure scheme for the vertical mixing, with k-epsilon parametrisation and Canuto type-A stability functions (Umlauf and Burchard 2003, 2005). At the bottom, a quadratic friction is applied, using a drag coefficient of $2.5 \cdot 10^{-3} \mathrm{~m} 2 / \mathrm{s} 2$. The horizontal tracers' advection scheme is QUICKEST (Leonard 1979), whereas the momentum advection formulation is calculated by applying a mixed total energy and potential enstrophy conserving scheme (Le Sommer et al. 2009). We use horizontal bilaplacian diffusion operators along geopotential levels, for both momentum eddy viscosity and tracers eddy diffusivity coefficients, with the values set at $-2.510^{8} \mathrm{~m} 4 / \mathrm{s}$ and $-2.510^{7} \mathrm{~m} 4 / \mathrm{s}$, respectively. A partial slip is used for the lateral boundary condition of the tangential velocity at the coasts.

\subsection{Model simulation and methods}

A "spin-up" simulation was carried out over a period of 6 years, using the realistic DFS5.2 atmospheric forcing and starting from Levitus98 climatology (Levitus et al. 1998), in order to reach steady state and allow the model to develop coherent structures representative of the regional circulation. Following this, a numerical simulation was performed spanning the period from December 1996 to March 1998. The investigation focuses on this period having as reference in- 
situ observations described by Johns et al. (2003), who deployed two subsurface moorings at the deepest part of the $\mathrm{SoH}$ adjacent to each other, at $26^{\circ} 16.0^{\prime} \mathrm{N}, 56^{\circ} 05.0^{\prime} \mathrm{E}$ (Fig. 1, white dot), with a separation of $400 \mathrm{~m}$.

In order to assess the modelling results and for validation against the available observations, we examine the physical properties of the exchange flow. The transport is calculated by integrating, at all levels, the longitudinal velocity $\mathrm{U}$ multiplied by the cross-section surface of the N-S axis of the SoH. The net transport is then as the sum of the daily fields. The temporal average refers to the entire period of the simulation (1996-1998). We have also normalized the transport by calculating the transport per unit depth, dividing the raw transport with the thickness of each level, to account for the variable levels based on the stretching of the vertical grid. This is the transport used for our analysis.

To examine the temporal variability of the vertical water mass exchange structure at the SoH, we apply a principal component (EOF) analysis on the daily net transport. In addition, the daily net transport is filtered with a 30-day cutoff frequency, using a fourth-order low-pass Butterworth filter, with the intention to investigate the seasonal and low-frequency variability, by means of the EOF analysis. The power spectral density (PSD) is used to examine the variability of the energy of the transport. The frequency function is calculated using Welch's overlapped segment averaging estimator (Welch 1967).

Cross-covariances were also calculated to investigate the spatio-temporal relationship between the wind forcing and the net transport at the SoH. The net transport is filtered with a 30-day cutoff frequency, using a fourth-order high-pass Butterworth filter, to exclude the seasonal cycle and focus on the synoptic band.

\section{Results and discussion}

\subsection{Model assessment}

The model outputs are first evaluated against the available observations, in terms of salinity, temperature and velocity profiles, as well as estimates of the net annual volume transport through the SoH. Figure 2 presents, with black lines, the temporal averaged velocity profiles at a specific model grid point, in the proximity of the mooring site investigated by Johns et al. (2003). The temporal averages are calculated over four bimonthly periods and for the year 1997 (representative also for other years during spin-up; not shown). The dense outflow occurs at depths greater than $40 \mathrm{~m}$, with maximum values near the sill. The seasonal variability of the deep outflow exhibits peak values during spring/summer, following the formation events of the previous winter, and minimum values during fall/winter. The net flow of the surface layers show a diverse pattern, shifting from net outflow during summer/fall to net inflow during winter/spring, overall compensating for the deep outflow of the AGW. The latter is a permanent feature in the SoH, occurring throughout the year.

The annual integrated transport per model level (Fig. 2, blue dots) shows a similar vertical structure to the mean velocity profile. The upper-layer $(\sim 40 \mathrm{~m}$ depth $)$ presents a relatively weak net inflow, with a peak of $0.01 \mathrm{~Sv}$, compared to the strong deep outflow, with a peak of about $0.04 \mathrm{~Sv}$ at depths near the sill. We also present the transport (Fig. 2, red line) computed per unit depth, as previously discussed. The model's annual mean transport is in good agreement with the transport estimated in the SoH by Johns et al. (2003). In their study, they found $0.23 \pm 0.04 \mathrm{~Sv}$ for the surface 
inflow on the northern side of the strait, $0.06 \pm 0.02 \mathrm{~Sv}$ of surface outflow on the south side, and $0.15 \pm 0.03 \mathrm{~Sv}$ for the deep outflow. The annual inflow based on daily model outputs was estimated at $0.22 \pm 0.01 \mathrm{~Sv}(0.15 \mathrm{~Sv}$ on the northern side of the strait, and at $0.07 \pm 0.01 \mathrm{~Sv}$ on the south side), and the deep outflow at $0.147 \pm 0.01 \mathrm{~Sv}$, which shows a reasonable agreement with the observations. Similarly, Pous et al. (2015) estimated 0.193 for the net inflow and 0.185 for the deep outflow.

The transport of the deep outflow (40 $\mathrm{m}$ to seafloor) exhibits significant seasonal variability (of a sinusoidal form; fig. 3), with small values during fall and large values during spring/early-summer. The maximum flow occurs in June whilst the minimum in October, with values $0.2 \mathrm{~Sv}$ and 0.08 Sv respectively. Hosseinibalam et al. (2011) and Pous et al. (2015) found similar seasonal variability and mean transport. Yao and Johns (2010) estimated a value of $0.12 \mathrm{~Sv}$, with maximum transport in summer and minimum transport in winter. Johns et al. (2003) found a maximum of $0.18 \mathrm{~Sv}$ occurring in March and a mean value of $0.15 \mathrm{~Sv}$, with weak seasonal variations in the deep outflow, in agreement with Swift and Bower (2003).

Time-longitude diagrams of temperature and salinity profiles in the $\mathrm{SoH}$, computed at the mooring site of Johns et al. (2003), are presented in Figure 4. Changes in salinity (Fig. 4a) are consistent with the altering inflow/outflow circulation pattern of the upper ocean layers at the SoH. Low salinity values in the surface occur between January and June 1997, which are typical of the water mass inflow from the Gulf of Oman. High salinity values in the surface characterized by the outflow water mass mixed with ambient saline waters inside the Gulf, are evident from August to November 1997. In addition, the AGW deep outflow has a higher salinity compared with the surface outflow and exhibits high intra-seasonal variability. The structure of the temperature profiles at the SoH (Fig. 4b) reveals a warm core in the upper ocean layers associated with the well stratified thermocline during summer, and intense cooling with reduced stratification during winter. The thermohaline structure in the SoH is also in close agreement with Johns et al. (2003).

\subsection{Spatio-temporal variability of the exchanges through the SoH}

The exchanges through the SoH present a complex spatial pattern, with high temporal variability. The transport vertical profile, as presented in Figure 2 (both per unit depth - red line, and per model level - blue dots), illustrates a relatively fresh net inflow of water from the Gulf of Oman, occurring in the upper layers to approximately a depth of $40 \mathrm{~m}$, and a highly saline outflow of AGW with increasing salinity with depth.

To establish the structure of this variability and examine its characteristic, we decompose the transport profile across the SoH into dominant components, using an EOF analysis. The decomposition reveals two dominant EOF modes that explain $93 \%$ of the total variance (Fig. 5). The first mode (Fig. 5a, b) explains $85.8 \%$ of the variance and has a quasi-barotropic structure. It presents a maximum near the surface and gradually reduces with depth, suggesting that the strongest variability occurs in the upper and intermediate layers, with a weaker signal in the deep layers. The temporal variations related to this mode (Fig. 5b) are clearly stronger during the winter period compared with other seasons and show high frequency fluctuations due to synoptic processes. The second EOF mode (Fig. 5c, d) explains $7.2 \%$ of the total variance and has a baroclinic structure, exhibiting a nearly similar vertical pattern to the annual mean transport (cf. Fig. 2, red line). The temporal variations of the second mode suggest that the flow is driven by the seasonal cycle, but also presents strong synoptic variability, though with moderately larger period in relation to the temporal variability of the 1 st mode. The seasonal enhancement of the transport 
follows the intensification of the buoyancy forcing in the Gulf during winter (Yao and Johns 2010) and presents a minimum exchange following the summer period.

In order to investigate the seasonal low-frequency variability of the exchange flows, we apply a low-pass filter of 30-days to the transport to exclude synoptic features. The EOF decomposition of the filtered transport reveals one dominant mode that explains $\sim 80 \%$ of the total variance (Fig. $5 \mathrm{c}, \mathrm{d}$, red lines), resembling the 2 nd mode of the unfiltered transport. Both modes exhibit important variability in the baroclinic flow of the vertical structure, i.e. for the upper layer inflow and the deep outflow. From late winter to early summer the mean transport profile and the first EOF mode of the unfiltered transport show a similar exchange pattern, resulting in an enhanced two-layer flow. In contrast, from mid-summer to mid-winter the exchange of the flow weakens, as the 1 st EOF mode opposes the mean transport profile. Both investigated filtered and unfiltered modes suggested that the temporal variability is related to the seasonal cycle (Fig. 5d).

Johns et al. (2003) characterized the 3D pattern of the exchange at the SoH, with an upper-ocean inflow at the northern part compensated by an outflow at the southern part of the SoH, which exhibits a seasonal variability. With the purpose of further examining the spatial variability at seasonal time scales, after applying a low-pass filter of 90-days, we calculate the average along the Strait velocity and decompose it into dominant EOF modes. The mean velocity cross-section (Fig. 6a) is consistent with the net transport exchange previously discussed in Figure 2. The exchange is of baroclinic nature, with an upper-layer inflow overlying a deep outflow, banked against the southern wall from the sub-surface layers to the bottom sill (Fig. 6a). The three dominant EOF modes of the filtered velocity explain $\sim 89 \%$ of the total variance (Fig. $6 \mathrm{~b}, \mathrm{~d}, \mathrm{f}$ ). The first mode explains $67 \%$ and exhibits high variability in the upper layers, being prominent in the southern part of the SoH (Fig. 6b). During late-winter to spring, the temporal mode of the first EOF is negative, resulting in a two-layer flow in the southern part of the Strait, while it is positive during summer to mid-autumn and early to mid-winter, indicating a seasonally varying exchange pattern (Fig. 6b, c), similar to the description by Johns et al. (2003). In the northern part of the Strait, where there is a baroclinic mean flow, the inflow is weakened, or even reverses to weak outflow, during the former period and enhanced during the latter. The second EOF (Fig. 6d, e) accounts for $12 \%$ of the total variance explained and present the highest variability in the central part of the SoH, exhibiting alternate lateral flows and an even more complex exchange pattern. The first two EOF modes can be related to the variable circulation suggested by Johns et al. (2003), i.e. the inflow occurring in the northern part of the strait partly recirculates to become a shallow outflow in the southern part. In Figure $6 \mathrm{f}$, the third EOF mode reflects the vertical variability of the flow, matching the previously described transport profile (cf. fig. 2), while explaining $10 \%$ of the variance. The temporal variations of the third mode (Fig. 6g) are similar to those extracted from the filtered transport profile (cf. fig. 5d). The latter confirms that the two-layer flow in late winter to early summer is enhanced, whilst is weakened from mid-summer to mid-winter.

The above results indicate a reasonable agreement with the estimates from observations reported by Johns et al. (2003), for the southern part of the Strait. The observations suggest a barotropic mean flow (outflow for the entire water column) for the entire period, except for March and April, when a two-layer flow appears. During these months the inflow was relatively weak, with the maximum mean deep outflow of the entire period occurring in March. Our results suggested that this two-layer flow pattern occurs over a broader period of time, i.e. from late-winter to spring and also in November. We also reveal, for the first time, a baroclinic mean flow (inflow), in the 
northern part of the SoH, that is enhanced during summer to mid-autumn and early to mid-winter, and weaken or even reversed to weak outflow during the remaining period.

In order to examine the synoptic scale processes, we have performed an EOF analysis using the high pass filtered velocity fields. We used an 8-day filter to effectively remove the seasonal cycle and highlight the high-frequency variations. The three dominant EOF modes of the filtered velocity explain $\sim 72 \%$ of the total variance (Fig. $7 \mathrm{~b}, \mathrm{~d}, \mathrm{f}$ ). The first mode explains $48 \%$ and has a quasi-barotropic structure, exhibiting large variability over almost the entire water column, being prominent in the southern and central part of the SoH (Fig. 7b). The temporal variations related to this mode (Fig. 7c) are consistent with those presented for the first EOF of the transport profile (cf. fig. 5b), exhibiting high-frequency fluctuations that intensify during winter. The second and third EOF modes (Fig. 7d, e, f, g) account for $12.8 \%$ and $10.6 \%$ of the total variance, respectively, and present an alternate lateral flow variability for the upper and intermediate layers across the $\mathrm{SoH}$. These modes are similar to the 2 nd EOF mode previously described for the low-pass filtered velocity (cf. Fig. 6d) and exhibit weaker temporal variability than the 1 st mode, being stronger from mid-winter to early-summer. This is related to the variability of the general circulation of the Gulf, rather than locally induced, but controlled by processes such as the cyclonic eddies described by Thoppil and Hogan (2009) and/or by the core meandering of the inflow as seen in Yao and Johns (2010).

\subsection{Transport attribution on synoptic time scales}

As discussed in the previous Section, the first EOF mode of the unfiltered transport is dominated by synoptic variability. To further support our argument, we applied a high-pass filter to the transport, in order to remove the low-frequency variability. The EOF analysis of the filtered signal revealed one dominant mode that explains $95 \%$ of the total variance. This fact, along with the enhancement of the second EOF mode from $7.2 \%$ to $80 \%$, when high-frequencies are excluded, indicates that the dominant processes controlling the water mass exchange through the $\mathrm{SoH}$, occur principally on synoptic time scales over a period of a few days and up to few weeks.

Aiming at attributing the EOFs to specific physical processes we examine the power spectral density of the water mass transport at the SoH (Fig. 8). The low frequency part of the power spectrum is related to the seasonal water mass exchange pattern. High energy spectra at seasonal time scales were illustrated for the deep part of the $\mathrm{SoH}$ at depths around $65-70 \mathrm{~m}$, matching the peak values at similar depths presented in the baroclinic EOF modes (Fig. 5c). This prominent feature reflects the high seasonal variability of the permanent deep outflow through the Gulf. In addition, the high energy spectra of the net inflow in the Gulf occurs from the surface down to a depth of $\sim 20 \mathrm{~m}$, paired with the upper layers of the two EOF modes displayed in Figure 5c.

The power spectrum shows a local maximum in depths ranging from surface to almost $35 \mathrm{~m}$ deep corresponding to a period of nearly four to five days, and two other local maxima from surface to approximately $10 \mathrm{~m}$ deep with a period of nearly three days. These three peaks in the highfrequency part of the power spectrum are related to the first EOF mode of the unfiltered transport, which presents maximum values at the same depths, as in Figure 5a.

Several studies have indicated that the exchange flow fluctuations in ocean straits are significantly impacted by local winds (e.g., Toulany et al. 1987, Lee and Williams 1988, Thoppil and Hogan 2009, Johns and Sofianos 2012, and Xie et al. 2019). Notably, Johns and Sofianos (2012) and Xie et al. (2019) suggested that, at synoptic time scales, the wind is the most important forcing 
mechanism driving the exchanges between the Red Sea and the Indian Ocean through the Bab-alMandeb strait. For the SoH, Thoppil and Hogan (2009) also evidenced that on short time scales, the variability of the flow is mainly wind driven. In order to examine the correlation of winds with the transport, we estimated the along-strait wind stress and volume transport, and we analyzed their temporal variability. The cross covariances of their signal are presented in Figure 9. Both the unfiltered (Fig. 9a) and the filtered transport are considered, by applying a high-pass filter of 30days, excluding the seasonal signal (Fig. 9b).

The SoH's transport variability shows a high correlation with local wind stress forcing (Fig. 9a). The positive correlation, at zero lag, indicates the direct response of the flow to local wind stress, mainly affecting the upper layers. On the other hand, when transport and wind forcing are negatively correlated, the influence on the vertical structure of the flow extends almost to the entire water column, with the flow responding to the wind forcing with a lag of two days. This quasibarotropic response is the outcome of wind blowing into (out of) the Gulf, with the associated transport resulting in water accumulation (deficit) in the basin, altering the sea level and generating a pressure gradient that, in turn, drives a quasi-barotropic flow out (in) of the basin. The lag of the response can be related to the size and the geometry of the basin and the strait (Johns and Sofianos 2012).

The results outline an even higher correlation when a high-pass filter is applied (Fig. 9b). Having excluded the lower frequencies, the cross covariances pattern is strengthened with respect to the unfiltered field. This pattern is well matched with the quasi-barotropic high frequency flow fluctuations, presented in the first EOF mode of the high pass filtered velocities discussed in the previous Section (fig 7b). This becomes more evident when we examine the lag correlation of the wind stress versus the temporal variations of the three dominant EOFs of the high pass filtered velocities (Fig. 10). There is a high correlation among local wind stress and the temporal variations of the first EOF mode (Fig.10 a), consistent with what is presented for the correlation of winds with the high pass filtered transport (Fig. 9b), i.e. negative correlation with a lag of $\sim 2$ days and positive correlation at zero lag. There is no correlation between the other two temporal modes and the wind stress, as it is shown in Figure 10b, c.

The previous analysis confirms the synoptic influence of the local wind to the transport. Moreover, the correlation lag reveals that the wind driven transport towards and from the Gulf can generate a delayed secondary response in the entire water column. A similar response has been described by Johns and Sofianos (2012) in the exchange flow variability at the Bab-al-Mandeb strait in the Red Sea, with an elevated response at the Helmholtz resonance period. In this study, a complex frequency-dependent behavior of the wind-driven transport through the Bab-al-Mandeb strait was suggested, which could even result in a transport out of the strait in response to winds blowing into the Red Sea, with an elevated response at the Helmholtz resonance period. A similar analysis will be conducted in a future work, incorporating longer time series of the strait response.

\section{Conclusions}

Using a high-resolution $\left(1 / 36^{\circ}\right)$ model simulation, this study, investigated on the water mass exchange variability through the Strait of Hormuz over the period from December 1996 to March 1998, during which observations are available. We focused on the mechanisms controlling the transport variability across the whole Strait, at synoptic time scales. The model results were found in good agreement with the observations, reproducing well the overall picture for the thermohaline structure and the temporal variability of the flow through the SoH. 
The annually integrated transport profile across the SoH resembles an anti-estuarine circulation, with a deep outflow of high salinity water, and an inflow of relatively fresher waters at the upper layers. The net annual inflow based on daily model outputs was estimated at $0.22 \pm 0.01 \mathrm{~Sv}$ and for the deep outflow at $0.147 \pm 0.01 \mathrm{~Sv}$, in close agreement with the observations.

Examination of the temporal evolution of the exchange flows reveals strong variability over various time scales. On long time scales, the variability of the flow relates to a baroclinic mode, mainly representing the seasonal cycle. The exchanges are intensified following an enhanced twolayer flow from late-winter through early-summer, while the flow diminishes from mid-summer to mid-winter. Strong variability is also evident in the upper layers from the south to the central part of the SoH, associated with the overturning circulation and seasonally varying complex inflow/outflow patterns. A baroclinic mean flow (inflow) is present in the northern part of the Strait. During late-winter to spring the inflow is weakened, or even reverses to weak outflow, whilst it is enhanced during summer to mid-autumn and early to mid-winter.

Although the seasonal pattern exerts a strong influence in the overall exchange intensity, our results reveal that the exchange flow variability is dominated by synoptic scale processes. Synoptic scale processes account for the major part of the variability and can considerably alter the inflow/outflow structure at the $\mathrm{SoH}$, with periods lasting from days to weeks. The variability over short time scales exhibits a quasi-barotropic pattern, affecting greatly the upper layers, with a mean period of 2 to 5 days. The intensity of these modulations also follows a seasonal cycle, with higher variability occurring after the winter period, when the exchange flow is also stronger.

Finally, it is shown that the synoptic variability of the exchanges at the $\mathrm{SoH}$ is strongly related to local wind stress forcing. The exchanges show a very high correlation with the local wind forcing over the SoH, with winds driving a direct positive response with enhanced correlation in the upper layers, and a negative response (opposite to the wind direction), with the maximum correlation at a 2-day lag that affects the entire water column. 


\section{Figure Captions}

Fig. 1 Model domain and bathymetry of the Arabian Gulf. The Strait of Hormuz is marked with red line and the mooring location of Johns et al. (2003) with white dot $\left(56.08^{\circ} \mathrm{E}\right.$ and $\left.26.26^{\circ} \mathrm{N}\right)$.

Fig. 2 Four bimonthly averages and the annual mean of velocity $(\mathrm{cm} / \mathrm{s})$ for the year 1997 (black lines) in the SoH close to Johns et al. (2003) mooring site. The blue dots represent the annual integrated transport in Sv, in each model level at the SoH. The red line represents the annual integrated transport per unit depth profile (Sv/m) at the SoH.

Fig. 3 Monthly mean values of the transport for the deep outflow (40m to seafloor) from the Strait.

Fig. 4 Hovmoller diagrams of model salinity (a) and temperature (b) in the SoH. A low-pass filter of 10 days is applied. The model data span the period from December 1997 to March 1998 in the SoH close to Johns et al. (2003) mooring site.

Fig. 5 First (a) and second (c, blue line) EOF modes of the SoH water mass transport, and their corresponding timeseries ( $b$ and d, blue line). Also, first EOF mode of the SoH water mass transport (c, red line) and the corresponding timeseries ( $\mathrm{d}$, red line), by applying a low-pass filter of 30 days.

Fig. 6 Cross section of averaged along Strait velocity for the whole duration, up (a), and the first three EOF velocity modes with their corresponding timeseries down (first mode b, c, second mode d, e, and third mode f, g). A 90-days low-pass filter was applied to the velocities.

Fig. 7 Cross section of averaged along Strait velocity for the whole duration, up (a), and the first three EOF velocity modes with their corresponding timeseries down (first mode b, c, second mode d, e, and third mode f, g). An 8-days high-pass filter was applied to the velocities.

Fig. 8 Power spectral density for the transport along the SoH calculated at the model's depths.

Fig. 9 Cross-covariance between the along-strait wind stress and the transport per unit depth in the SoH (a), and (b) the same by applying a high-pass filter of 30 days.

Fig. 10 Lag correlation of the along strait wind stress versus the temporal variations of the three dominant EOFs of the high pass filtered velocities. 


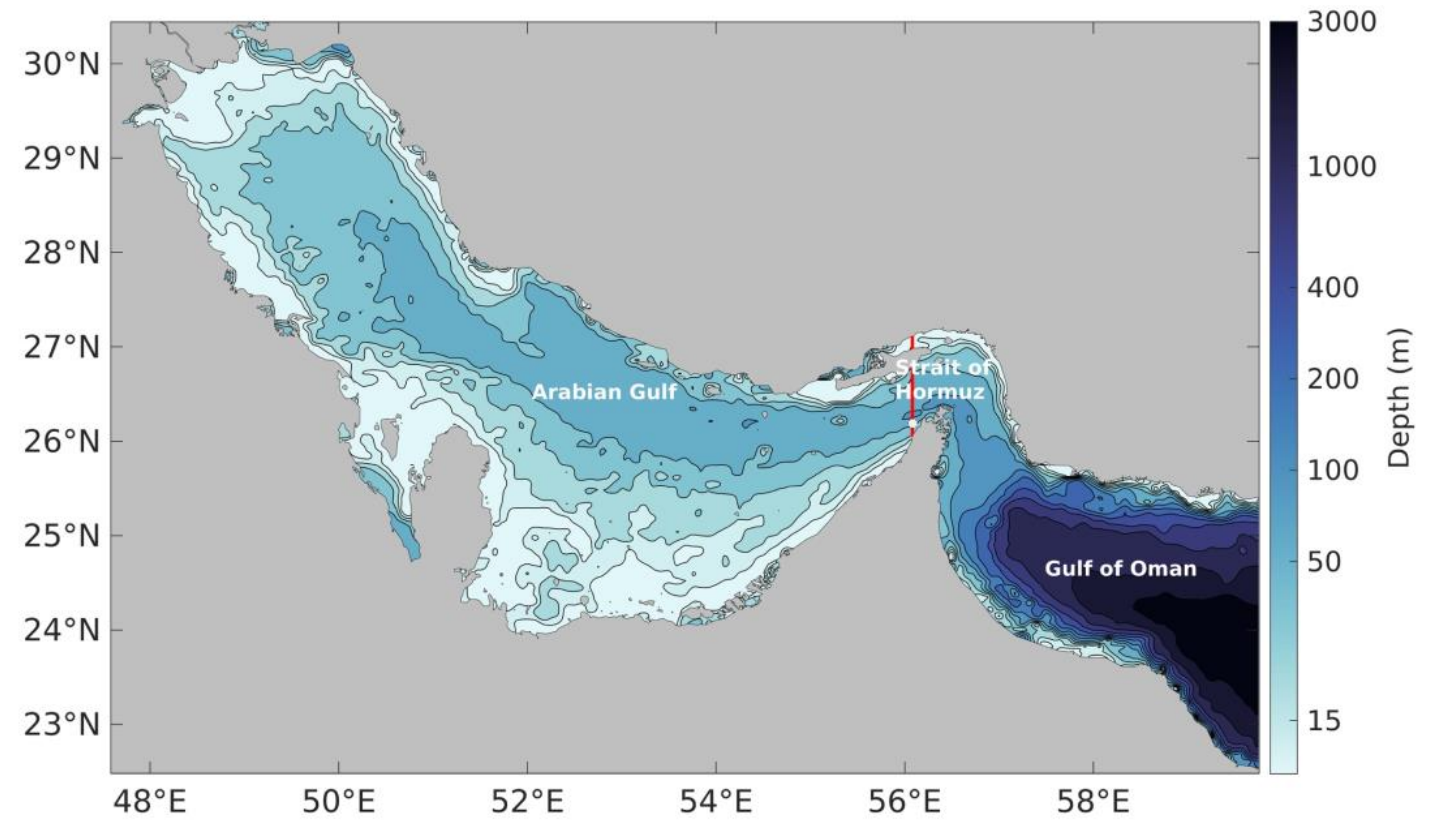

Fig. 1 Model domain and bathymetry of the Arabian Gulf. The Strait of Hormuz is marked with red line

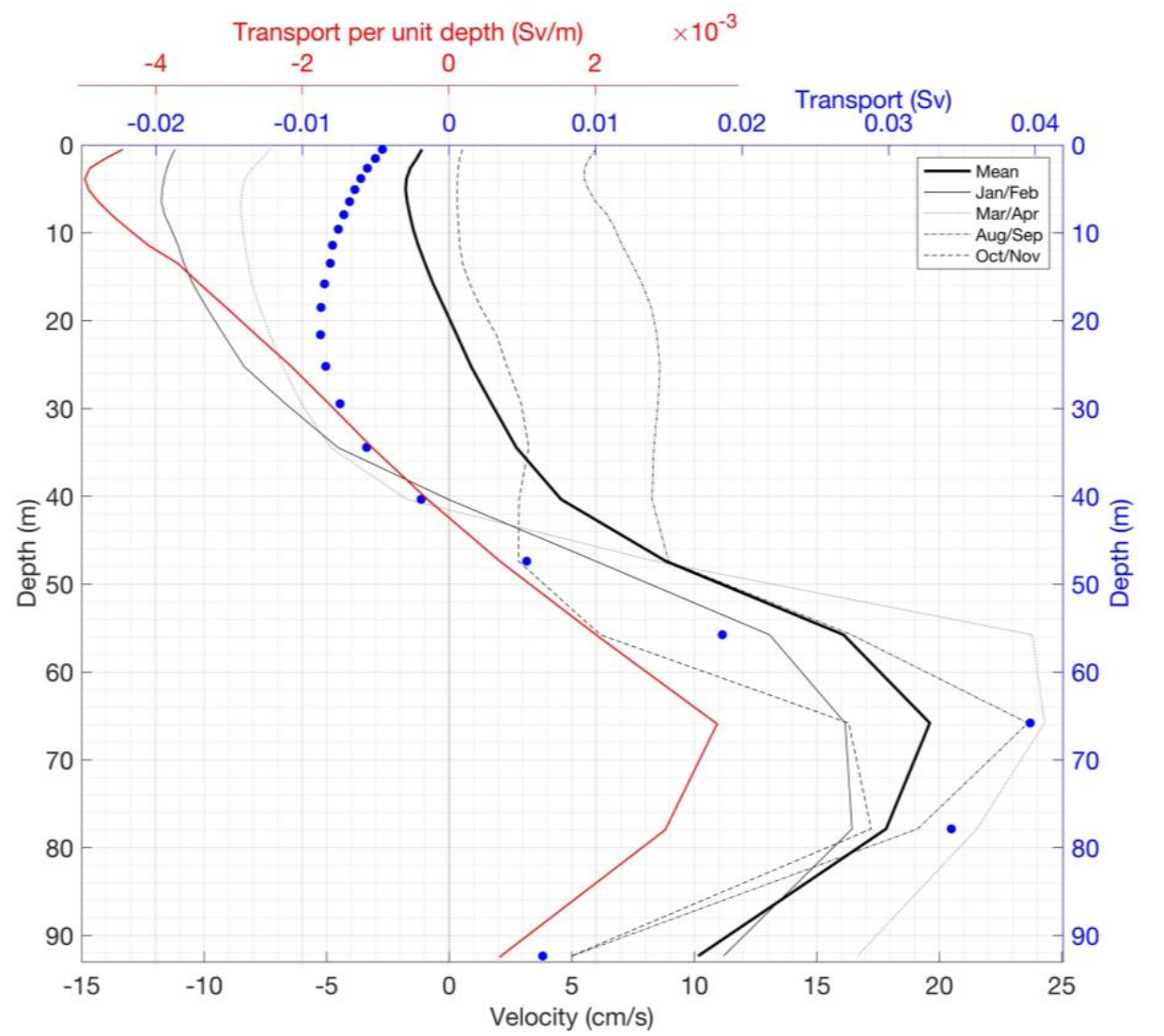

Fig. 2 Averaged velocity profiles (cm/s) of four bimonthly intervals and of the year 1997 (black lines) in the SoH close to Johns et al. (2003) mooring site, and annual integrated transport (Sv) in the SoH (blue line) 


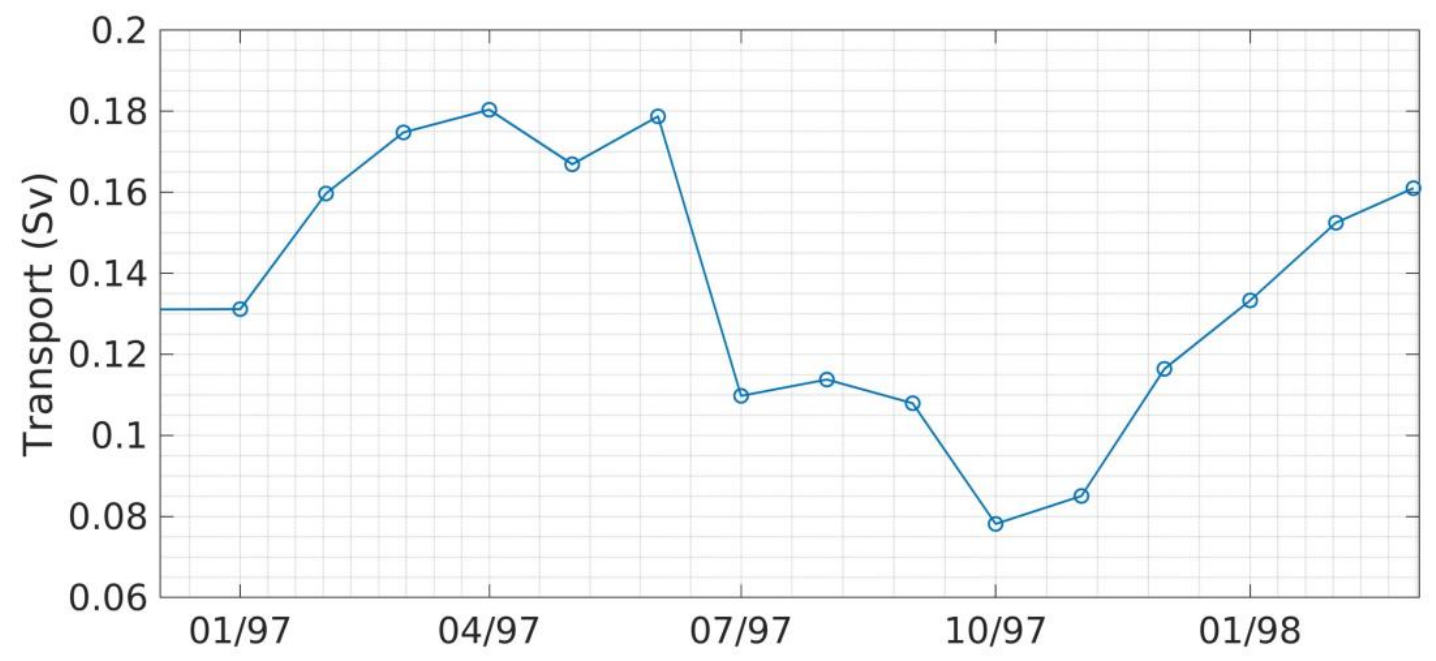

Fig. 3 Monthly mean values of the transport for the deep outflow (45m to seafloor) from the Strait.
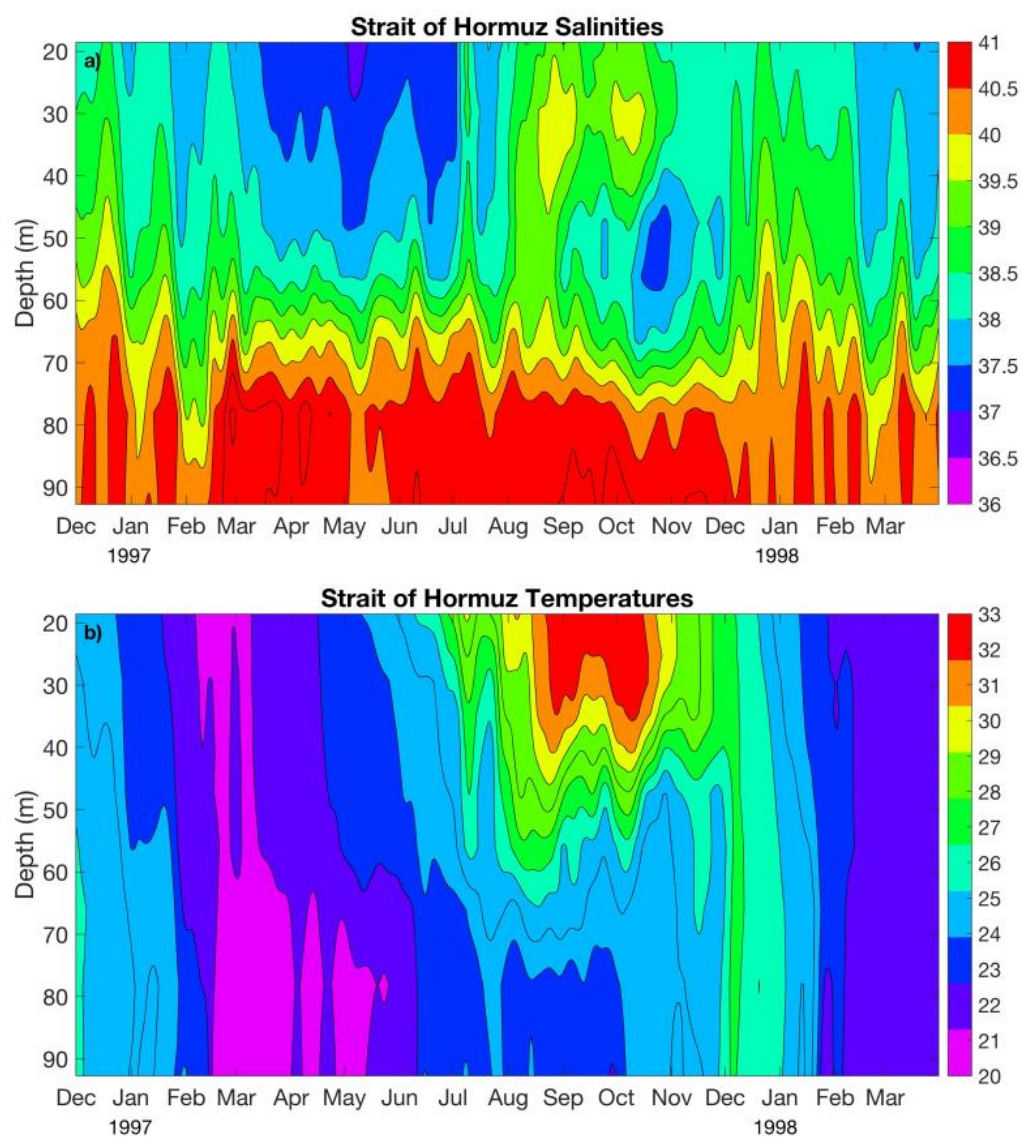

Fig. 4 Hovmoller diagrams of model salinity (a) and temperature (b) in the SoH. A low-pass filter of 10 days is applied. The model data span the period from December 1997 to March 1998 in the SoH close to Johns et al. (2003) mooring site 

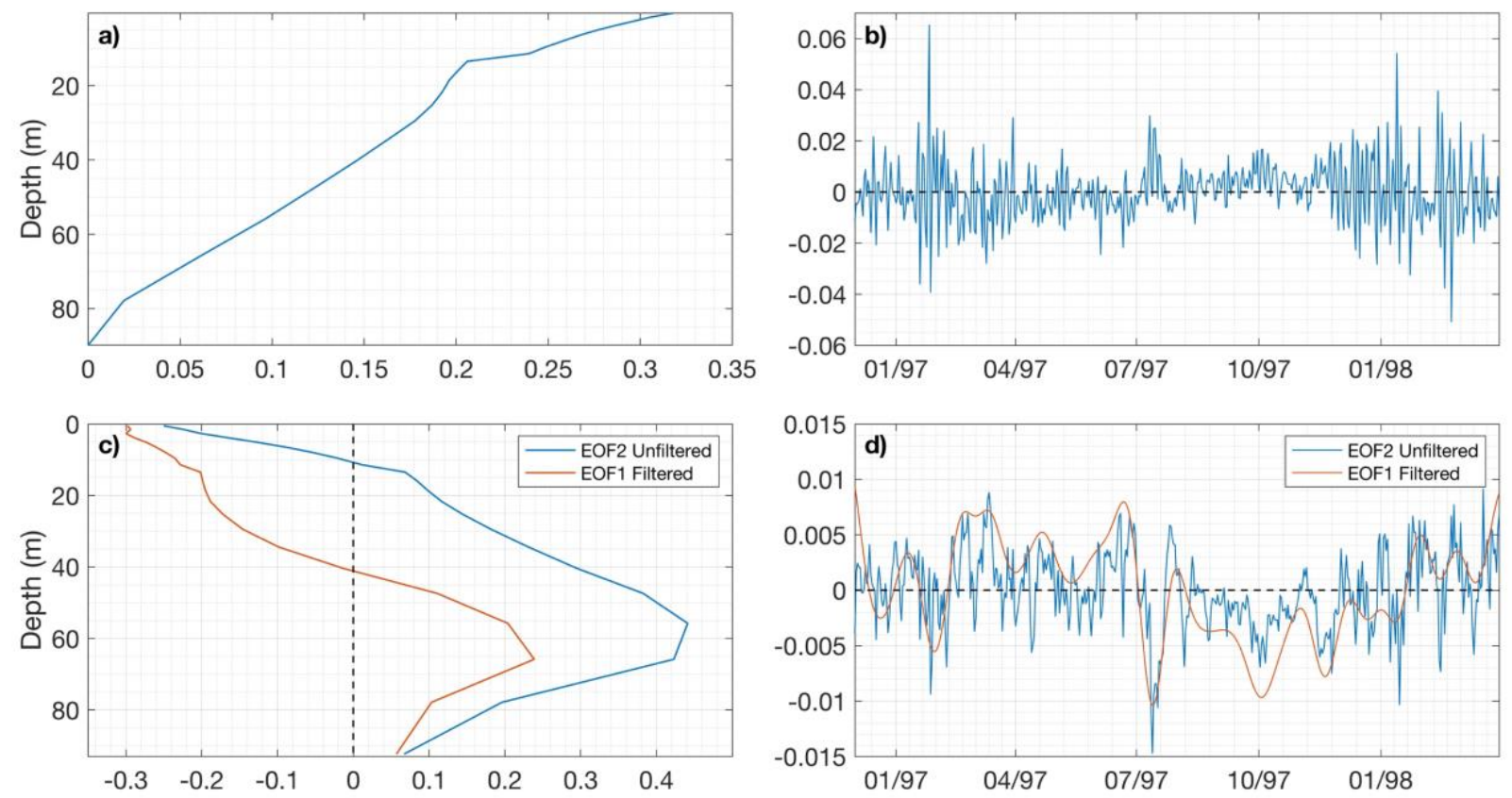

Fig. 5 First (a) and second (c, blue line) EOF modes of the SoH water mass transport, and their corresponding timeseries ( $b$ and d, blue line). Also, first EOF mode of the SoH water mass transport (c, red line) and the corresponding timeseries (d, red line), by applying a low-pass filter of 30 days 

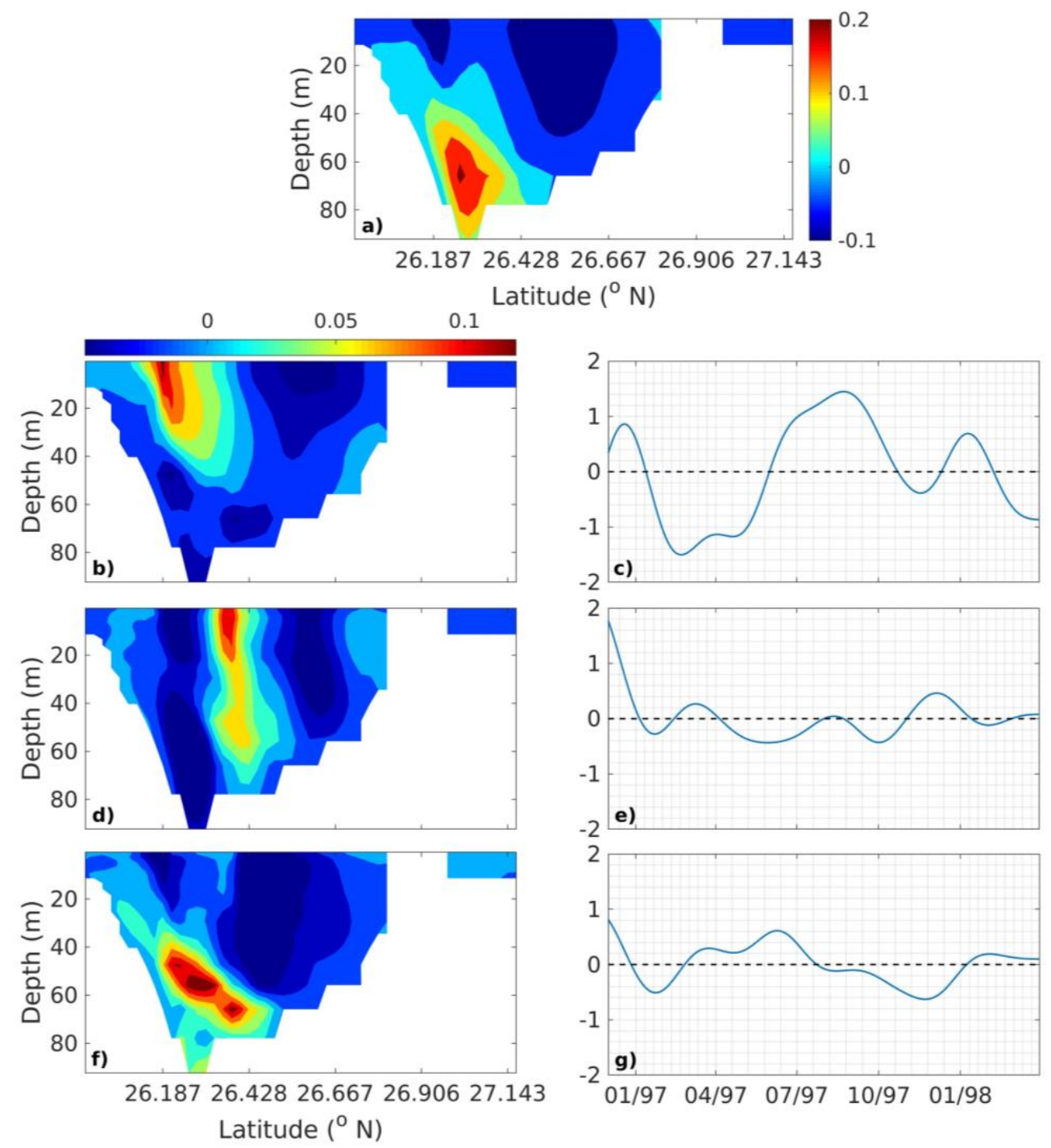

Fig. 6 Cross section of averaged along Strait velocity for the whole duration, up (a), and the first three EOF velocity modes with their corresponding timeseries down (first mode b, c, second mode d, e, and third mode f, g). A low-pass filter was applied to the velocities 

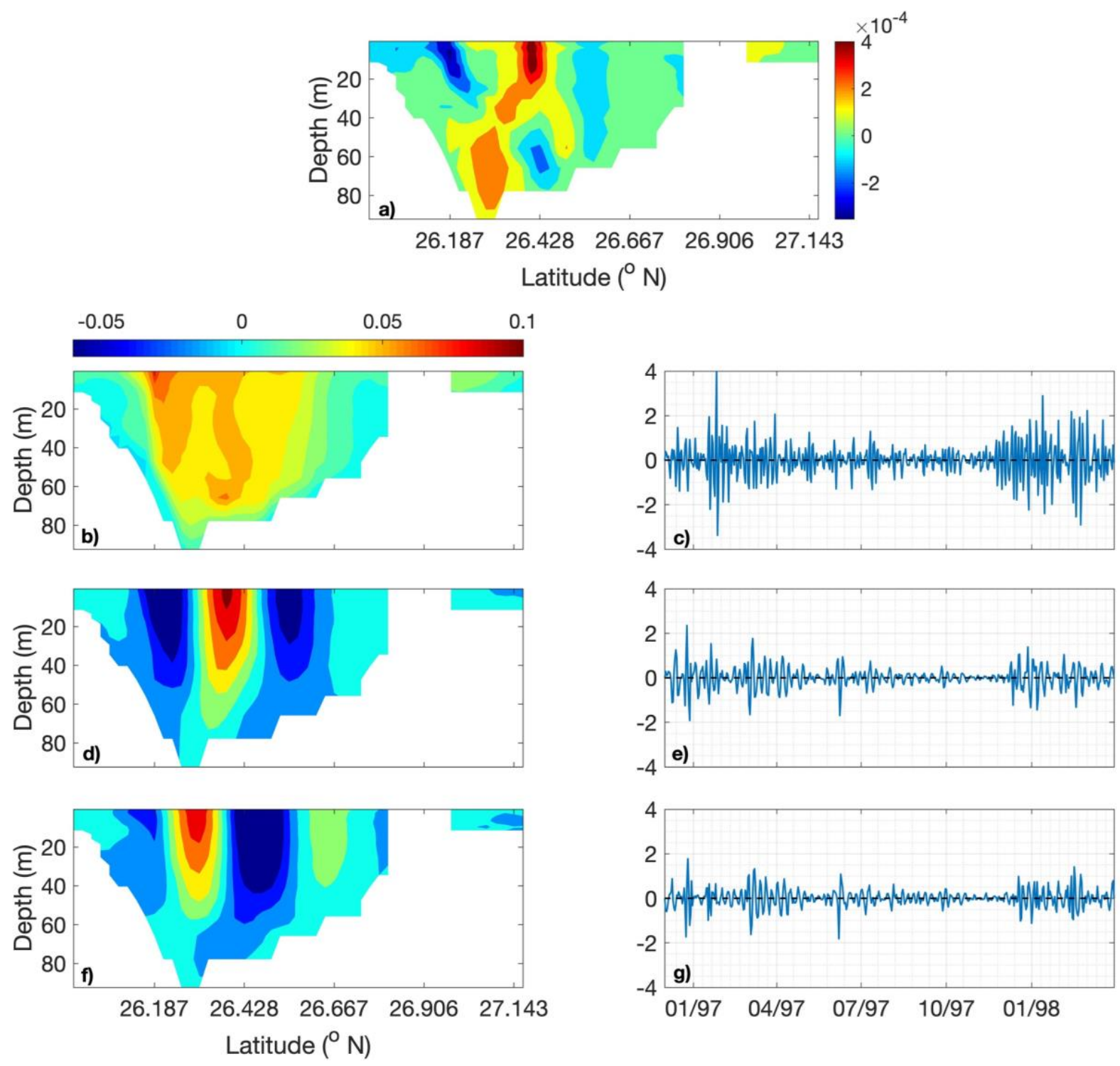

Fig. 7 Cross section of averaged along Strait high-pass filtered velocity for the whole duration, up (a), and the first three EOF velocity modes with their corresponding timeseries down (first mode b, c, second mode d, e, and third mode $\mathrm{f}, \mathrm{g})$. 


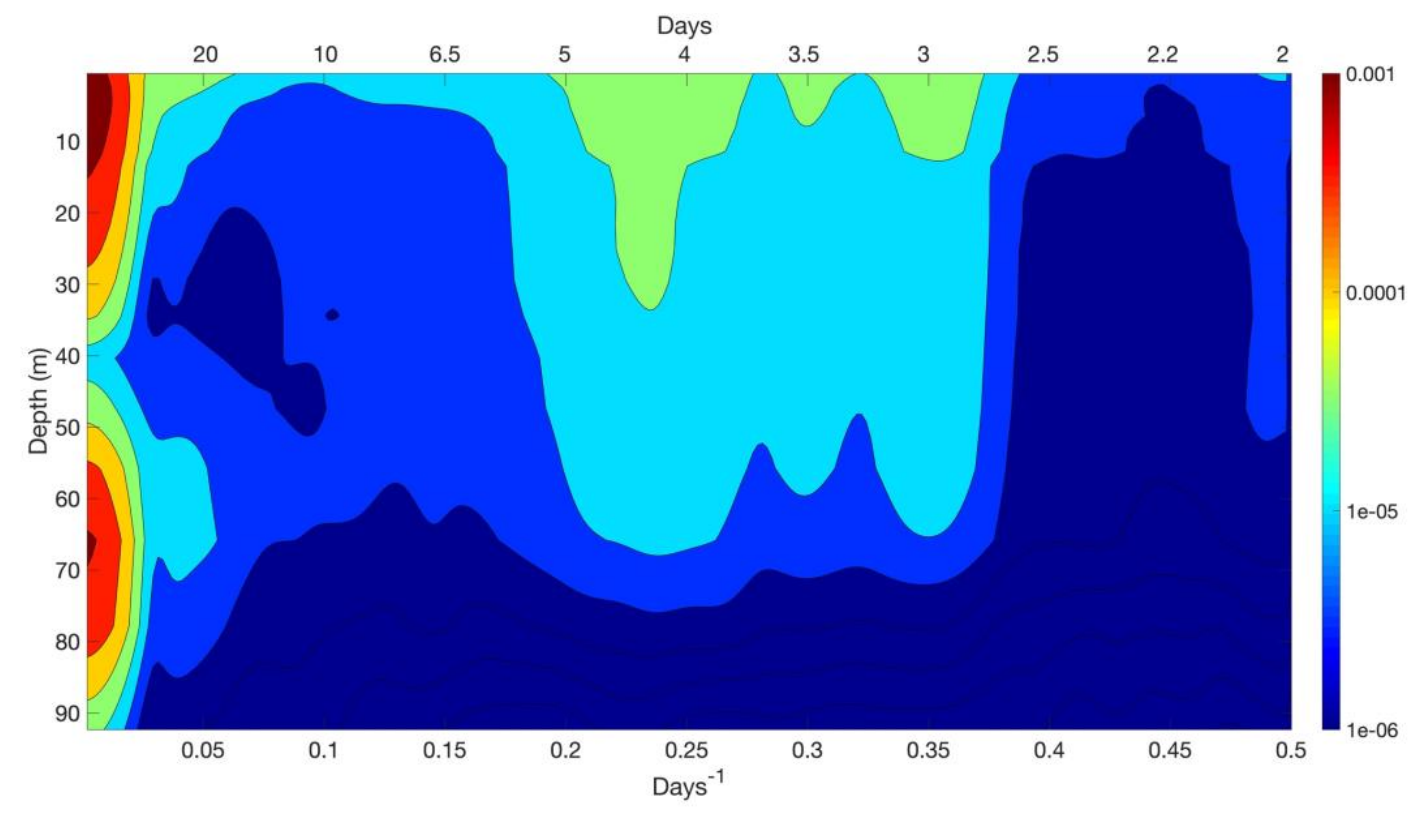

Fig. 8 Power spectral density for the transport along the SoH calculated at the model's depths

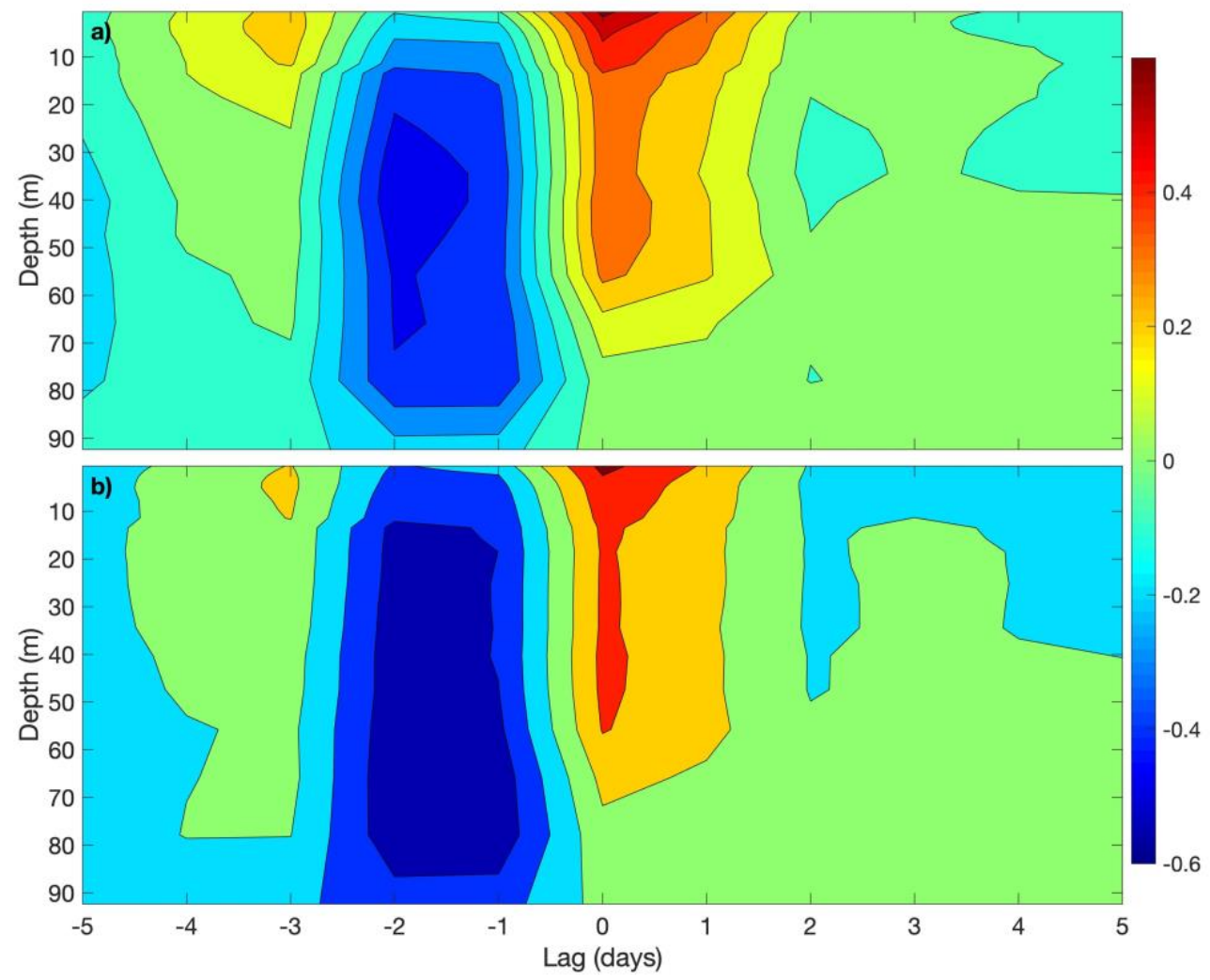

Fig. 9 Cross-covariance between wind stress and transport in the $\mathrm{SoH}$ (a), and (b) the same by applying a high-pass filter of 30 days 

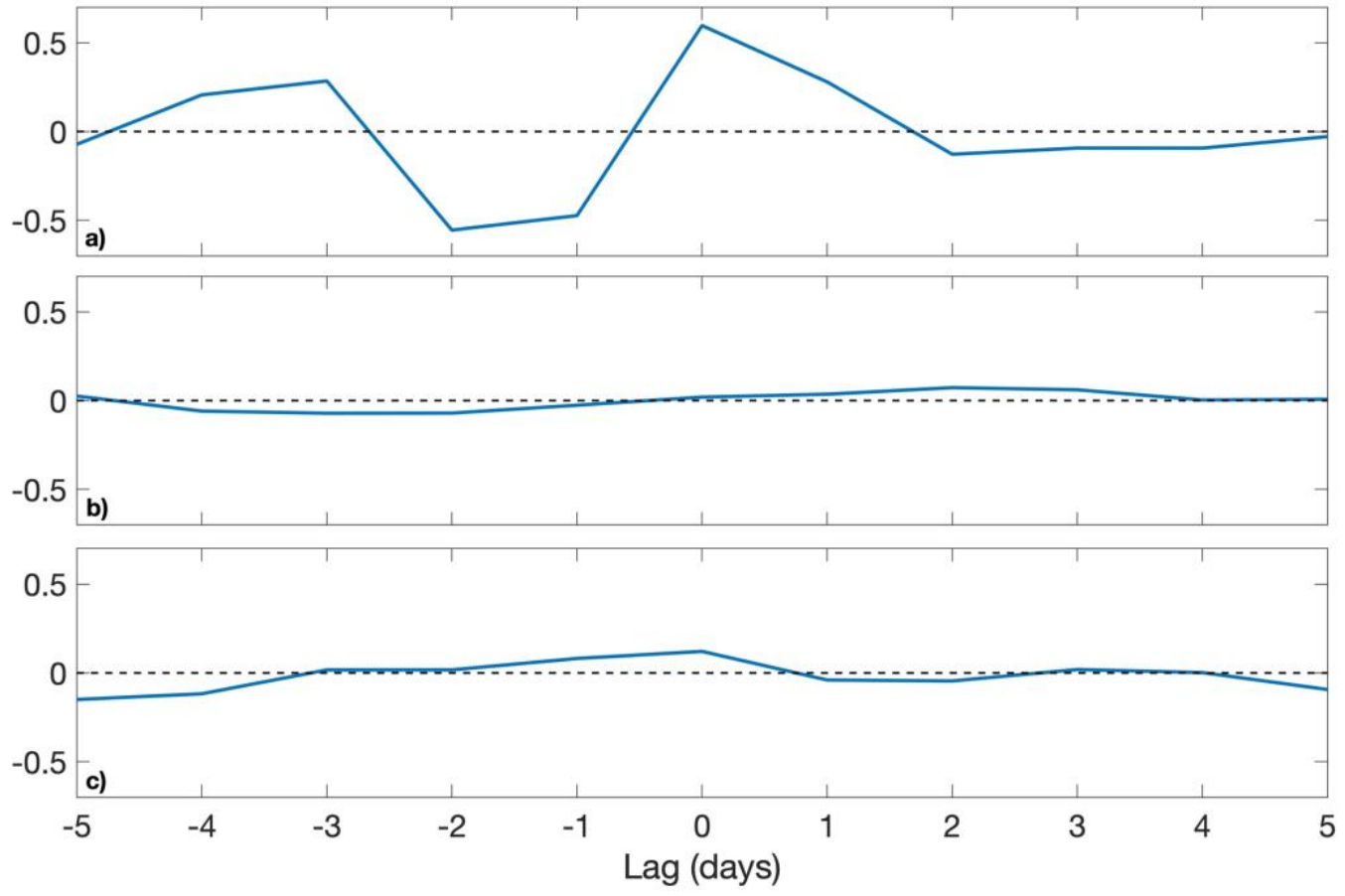

Fig. 10 Lag correlation of the along strait wind stress versus the temporal variations of the three dominant EOFs of the high pass filtered velocities. 


\section{References}

Al Azhar, M, Temimi M, Zhao J, Ghedira H (2016) Modeling of circulation in the Arabian Gulf and the Sea of Oman: Skill assessment and seasonal thermohaline structure. J Geophys Res Oceans 121: 1700-1720. doi:10.1002/2015JC011038

Al Shehhi MR, Gherboudj I, Ghedira H (2014) An overview of historical harmful algae blooms outbreaks in the Arabian Seas. Mar Pollut Bull 86:314-324. doi: 10.1016/j.marpolbul.2014.06.048

Barnier B, Madec G, Penduff T, et al (2006) Impact of partial steps and momentum advection schemes in a global ocean circulation model at eddy-permitting resolution. Ocean Dyn 56:543-567. doi: 10.1007/s10236-0060082-1

Bleck R, Halliwell GR, Wallcraft AJ, Carroll S, Kelly K, Rushing K, (2002) Hybrid Coordinate Ocean Model (HYCOM) user's manual: Details of the numerical code. HYCOM Consortium, 211 pp. http://hycom.rsmas. miami.edu.

Bleck R (2002) An oceanic general circulation model framed in hybrid isopycnic-Cartesian coordinates. Ocean Modell 4(1): 55-88. doi: 10.1016/S1463-5003(01)00012-9

Brewer PG, Dyrssen D (1985) Chemical oceanography of the Persian Gulf. Prog Oceanogr 14:41-55. doi: 10.1016/0079-6611(85)90004-7

Brewer PG, Fleer AP, Kadar S, Smith CL (1978) Report A, chemical oceanographic data from the Persian Gulf and Gulf of Oman. Woods Hole Oceanographic Institution, Woods Hole, MA. doi: 10.1575/1912/10603

Chao SY, Kao TW, Al-Hajri KR (1992) A numerical investigation of circulation in the Arabian Gulf. J Geophys Res 97:11219-11236. doi: 10.1029/92jc00841

Dussin R, Barnier B, Brodeau L (2014) The making of Drakkar forcing set DFS5. DRAKKAR/MyOcean Rep: 0510.

Egbert GD, Erofeeva SY (2002) Efficient inverse modeling of barotropic ocean tides. J Atmos Ocean Technol 19:183-204. doi: 10.1175/1520-0426(2002)019<0183:EIMOBO>2.0.CO;2

Essa S, Harahsheh H, Shiobara M, Nishidai T (2005) Chapter 3 Operational remote sensing for the detection and monitoring of oil pollution in the arabian gulf: Case studies from the United Arab emirates. Dev Earth Environ Sci 3:31-48. doi: 10.1016/S1571-9197(05)80027-8

Emery KO (1956) Sediments and Water of Persian Gulf. Am Assoc Pet Geol Bull 40:2354-2383. doi: 10.1306/5ceae595-16bb-11d7-8645000102c1865d

Flather RA (1994) A storm surge prediction model for the northern Bay of Bengal with application to the cyclone disaster in April 1991. J Phys Oceanogr 24:172-190. doi: 10.1175/15200485(1994)024<0172:ASSPMF>2.0.CO;2

Fukuoka A (1951) The Central Meteorological Observatory, A study on 10-day forecast (A synthetic report). Japan Meteorological Agency

Gherboudj I, Ghedira H (2014) Spatiotemporal assessment of dust loading over the United Arab Emirates. Int J Climatol 34:3321-3335. doi: 10.1002/joc.3909

Halliwell GR (2004) Evaluation of vertical coordinate and vertical mix- ing algorithms in the Hybrid-Coordinate Ocean Model (HYCOM). Ocean Modell 7(3-4): 285-322. doi: 10.1016/j.ocemod.2003.10.002

Hosseinibalam F, Hassanzadeh S, Rezaei-Latifi A (2011) Threedimensional numerical modeling of thermohaline and wind-driven circulations in the Persian Gulf. Applied Mathematical Modelling 35(12):5884-5902. doi: 10.1016/j.apm.2011.05.040

Hunter JR (1982) The physical oceanography of the Arabian Gulf: a review and theoretical interpretation of previous observations. In the First Arabian Gulf Conference on Environment and Pollution. Kuwait University, Faculty of Science, Kuwait: pp 1-23

Hyder P,While J, Arnold A, et al (2014) Evaluating a new NEMO-based Persian/Arabian Gulf tidal operational model. Journal of Operational Oceanography 6(1):3-16. doi: 10.1080/ 1755876X.2013.11020140

Johns WE, Yao F, Olson DB, et al (2003) Observations of seasonal exchange through the Straits of Hormuz and the inferred heat and freshwater budgets of the Persian Gulf. J Geophys Res C Ocean 108:21-1. doi: 10.1029/2003jc001881

Johns WE, Sofianos S (2012) Atmospherically Forced Exchange through the Bab el Mandeb Strait. J Phys Oceanogr 42(7):1143- 1157. doi: 10.1175/JPO-D-11-0157.1

Kämpf J, Sadrinasab M (2006) The circulation of the Persian Gulf : a numerical study 2: 129-164. doi: 10.5194/os2-27-2006

Lazure P, Dumas F (2008) An external-internal mode coupling for a 3D hydro- dynamical model for applications at regional scale (MARS). Adv Water Resour 31 (2): 233-250. doi: 10.1016/j.advwatres.2007.06.010 
Le Sommer J, Penduff T, Theetten S, et al (2009) How momentum advection schemes influence current-topography interactions at eddy permitting resolution. Ocean Model 29:1-14. doi: 10.1016/j.ocemod.2008.11.007

Lee TN, Williams E (1988) Wind-Forced Transport Fluctuations of the Florida Current. J Phys Oceanogr 18:937946. doi: 10.1175/1520-0485(1988)018<0937:WFTFOT>2.0.CO;2

Leonard BP (1979) A stable and accurate convective modelling procedure based on quadratic upstream interpolation. Comput Methods Appl Mech Eng 19:59-98. doi: 10.1016/0045-7825(79)90034-3

Levitus S, Conkright M, Boyer T, et al (1998) World Ocean Database 1998 NOAA Atlas

NESDIS 1: 346 pp.

Madec, G (2012) Nemo ocean engine, Tech. rep., NEMO team. http://www.nemo-ocean.eu/

Matsuyama M, Kitade Y, Senjyu T, et al (1998) Vertical structure of a current and density front in the Strait of Hormuz. Offshore Environ ROPME Sea Area After War-Related Oil Spill, Ed by A Otsuki, M Y Abdulraheem, R M Reynolds 3:23-34, Terra Sci., Tokyo

Pous S, Carton X, Lazure P (2013) A Process Study of the Wind-Induced Circulation in the Persian Gulf. Open J Mar Sci 03:1-11. doi: 10.4236/ojms.2013.31001

Pous S, Lazure P, Carton X (2015) A model of the general circulation in the Persian Gulf and in the Strait of Hormuz: Intraseasonal to interannual variability. Continental Shelf Research 94: 55-70. doi: 10.1016/j.csr.2014.12.008

Reynolds RM (1993) Physical oceanography of the Gulf, Strait of Hormuz, and the Gulf of Oman-Results from the Mt Mitchell expedition. Mar Pollut Bull 27:35-59. doi: 10.1016/0025-326X(93)90007-7

Richlen ML, Morton SL, Jamali EA, et al (2010) The catastrophic 2008-2009 red tide in the Arabian gulf region, with observations on the identification and phylogeny of the fish-killing dinoflagellate Cochlodinium polykrikoides. Harmful Algae 9:163-172. doi: 10.1016/j.hal.2009.08.013

Shchepetkin AF, McWilliams JC (2005) The regional oceanic modeling system (ROMS): A split-explicit, freesurface, topography-following-coordinate oceanic model. Ocean Model 9:347-404. doi: 10.1016/j.ocemod.2004.08.002

Swift SA, Bower AS (2003) Formation and circulation of dense water in the Persian/Arabian Gulf. J Geophys Res C Ocean 108:4-1. doi: 10.1029/2002jc001360

Thoppil PG, Hogan PJ (2009) On the mechanisms of episodic salinity outflow events in the Strait of Hormuz. J Phys Oceanogr 39:1340-1360. doi: 10.1175/2008JPO3941.1

Toulany B, Petrie B, Garrett C (1987) The frequency-dependent structure and dynamics of flow fluctuations of Strait of Belle Isle. J Phys Ocean 17:185-196. doi: 10.1175/1520-0485(1987)017<0185:TFDSAD>2.0.CO;2

Umlauf L, Burchard H (2003) A generic length-scale equation for geophysical turbulence models. J Mar Res 61:235-265. doi: 10.1357/002224003322005087

Umlauf L, Burchard H (2005) Second-order turbulence closure models for geophysical boundary layers. A review of recent work. Cont Shelf Res 25:795-827. doi: 10.1016/j.csr.2004.08.004

Weatherall P, Marks KM, Jakobsson M, et al (2015) A new digital bathymetric model of the world's oceans. Earth Sp Sci 2:331-345. doi: 10.1002/2015EA000107

Welch PD (1967) The Use of Fast Fourier Transform for the Estimation of Power Spectra: A Method Based on Time Averaging Over Short, Modified Periodograms. IEEE Trans Audio Electroacoust 15:70-73. doi: 10.1109/TAU.1967.1161901

Xie J, Krokos G, Sofianos S, Hoteit I (2019) Interannual Variability of the Exchange Flow Through the Strait of Bab-al-Mandeb. J Geophys Res Ocean 124:1988-2009. doi: 10.1029/2018JC014478

Yao F, Johns WE (2010) A HYCOM modeling study of the Persian Gulf: 2. Formation and export of Persian Gulf Water. J Geophys Res Ocean 115:. doi: 10.1029/2009JC005788

Zhao J, Ghedira H (2014) Monitoring red tide with satellite imagery and numerical models: A case study in the Arabian Gulf. Mar Pollut Bull 79:305-313. doi: 10.1016/j.marpolbul.2013.10.057

Zhao J, Temimi M, Al Azhar M, Ghedira H (2015) Satellite-based tracking of oil pollution in the Arabian Gulf and the Sea of Oman. Can J Remote Sens 41:113-125. doi: 10.1080/07038992.2015.1042543

Zhao J, Temimi M, Ghedira H, Hu C (2014) Exploring the potential of optical remote sensing for oil spill detection in shallow coastal waters-a case study in the Arabian Gulf. Opt Express 22:13755. doi: 10.1364/oe.22.013755 